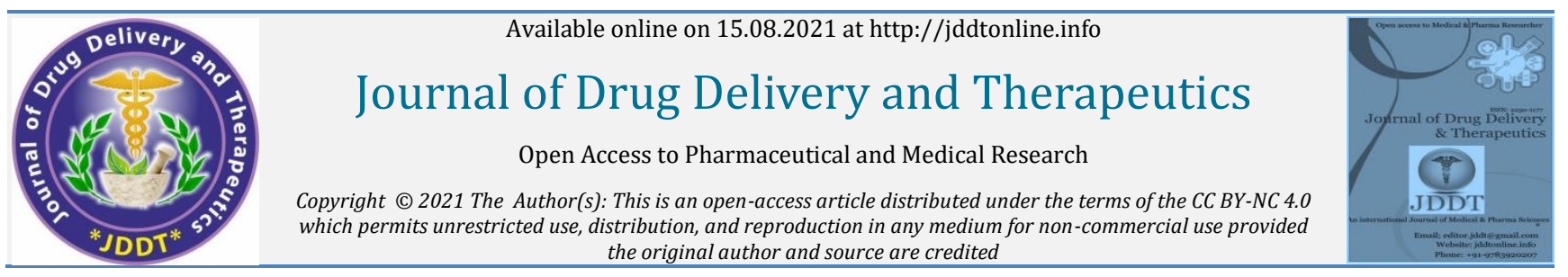

Open Access Full Text Article the original author and source are credited
and reproduction in any medium

Review Article

\title{
Experimental Design: Approaches and Applications in Development of Pharmaceutical Drug Delivery System
}

\author{
Supare Vinanti*, Wadher Kamlesh (D), Umekar Milind \\ Department of Pharmaceutics, Smt. Kishoritai Bhoyar College of Pharmacy, Kamptee, Nagpur, Maharashtra, India 441002
}

\begin{tabular}{ll}
\hline Article Info: \\
\end{tabular}

Cite this article as:

Supare V, Wadher K, Umekar M, Experimental Design: Approaches and Applications in Development of Pharmaceutical Drug Delivery System, Journal of Drug Delivery and Therapeutics. 2021; 11(4-S):154-161

DOI: http://dx.doi.org/10.22270/jddt.v11i4-S.4908

*Address for Correspondence:

Vinanti Supare, Department of Pharmaceutical Technology, Smt. Kishoritai Bhoyar College of

Pharmacy, Kamptee, Nagpur, Maharashtra, India 441002

ORCID ID: https://orcid.org/0000-0002-3782-3380

\author{
Abstract
}

Conventionally, all the delivery systems have been prepared by methodology of trial and error concept by manipulating one variable at a Time, but attainment of optimal formulation is not achievable. The systematic approach Design of Experiments (DoE) enables researchers to provide appropriate outline to develop a best optimized delivery system. Optimization techniques using DoE helps to provide effective and economical analytical tools to find the perfect solution for a particular problem. In screening designs, there is large number of screening factors in minimum number of experiments and beneficial to minimize the variables in a desired size therefore further experimentation may be performed easily by using these variables. Experimental designs and optimization techniques are the tools which are systematically used to categorize various types of problems that may influence development of pharmaceutical delivery system. Use of experimental design is the best approach to the screening and optimization of experimental factors. In the present review article we have focused on application of practically applicable experimental designs and optimization techniques for the development of quality and efficacious of pharmaceutical formulations such as, nanoparticles, Phytosomes, microspheres, liposomes, micells, films, nanostructured lipid carriers and tablets and which type of factors to be considered while optimization are also discussed.

Keywords: Experimental design, Optimization, Applications, Drug delivery, Phytosomes, Nano delivery System.

\section{INTRODUCTION:}

The development of an effective delivery system involves rational combinations of various polymers and additives. The conventional approach of optimizing a formulation or process generally entails study of the influence of one variable at a time while keeping others as constant. Using this approach the attainment of the true optimum formulations or process is always unconvinced and the technique is highly tedious, time consuming as it leads to carry out unnecessary runs and formulation batches. ${ }^{1}$

The formulation of dosage form is tedious and expensive, therefore to minimize this problem there is need to develop and optimize the formulation to get the robust and efficacious pharmaceutical product. Experimental design is a method to optimize the formulation by performing minimum number of experiment for getting proper information which is necessary to perform the experiment. The screening experiments are beneficial to minimize the variables in a desired size therefore further experiment may be performed easily by using these variables which are useful to understand the whole procedure of experiment. ${ }^{2}$

\section{EXPERIMENTAL DESIGN:}

Experimental design is a design in which some factors can be evaluated at several numbers of levels in a definite number of experiments. Experimental design can be classified into Screening designs and Response surface designs..$^{3-5}$ In screening designs, there is screening of large number of factors in small number of experiments hence numbers of experiment may be reduced. This design is used to find out the most influencing factors which are evaluated only at two levels. Response surface design is the design which is used to optimize the levels in an experiment. The factors are optimized at minimum three levels after that the final result originates from the response surfaces which is developed in the design. Mixture design is also a response surface design that is used in mixture related factors in a given experiment. When the mixture of all factors in experiments is to be optimized then this type of design is used. For example: In chromatography, organic modifiers in a mobile phase, or the various excipients used in preparation of tablet or any other formulations in pharmaceutical industry. In this type of factors, which designs are used is totally depend on number and type of factors based on their purpose and also depend on analyst.

Experimental designs are useful in various pharmaceutical as well as other fields of sciences. The application of experimental design includes optimization of separation methods, process optimization to yield maximum product, optimization of formulation and pharmaceutical products, or processes. In our area of interest, the first application of 
experimental design in separation science i.e., to separate and identify the valuable product in given components by developing analytical assay and their selection of techniques that means validation and optimization of the method.6-8

The most important application of experimental design which is mainly focus in this paper is the optimization of pharmaceutical formulations, products, or manufacturing process. In manufacturing process, the manufacturing of formulations is performed by batch processing unit. Experimental designs are broadly classified into two types such as Factorial design and Response Surface design as shown in figure 1. A factorial design is a screening design which consists of full factorial design, Plackett -Burman design and Fractional factorial design. For the optimization, response surface design was used which is Central composite design and Box- Behnken design.

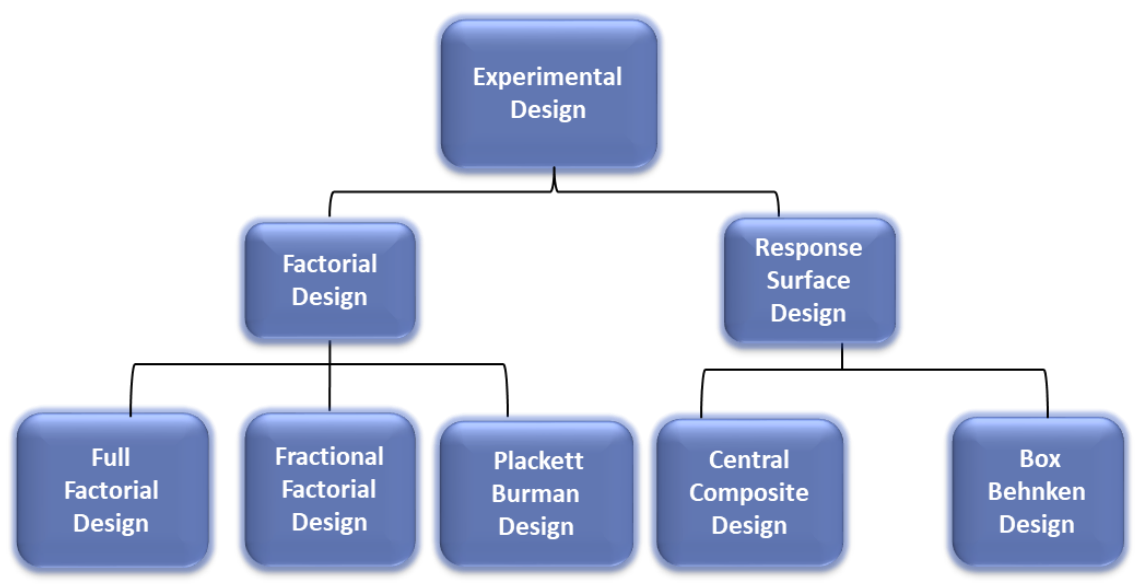

Figure 1: Classification of Experimental design

Depending on the factors to be used in experimental design, full factorial designs are of two types such as full two level factorial designs and full three level factorial designs. A two level full factorial design is a common type of screening design for the identification of significant parameters. Full factorial design is denoted by $2 \mathrm{k}$ where $\mathrm{k}$ is the number of factors that are studied in two levels i.e. high (+1) and low ($1)$. In this design, the number of experiment increases as the number of factors increased. ${ }^{9}$

\section{APPLICATION OF EXPERIMENTAL DESIGN:}

The use of experimental design is the best approach to the screening and optimization of experimental factors. Simple experimental design can provide better information in very few experiments within minimum time period. Experimental design is very important tool in process development, analytical method development \& purification, biological process as well as in delivery system as mentioned in figure 2.

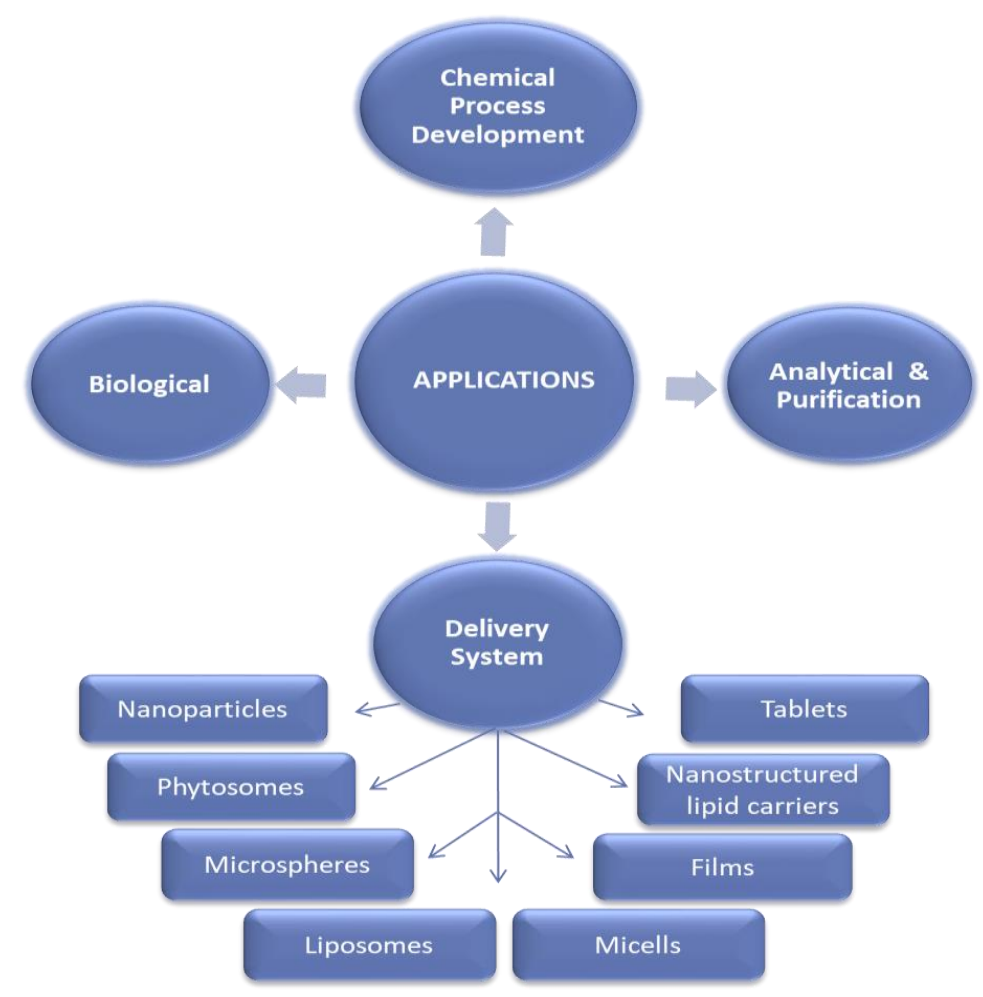

Figure 2.: Applications of Experimental Design 


\section{Chemical process development -}

Experimental design is a key factor in the optimization of reactions protocol for the successful drug manufacturing process. With the help of experimental design, a strong and defendable system can find out in a short time period with affordable price. The use of experimental design is beneficial in comparison to traditional methods. In case of automatic system, the use of experimental design is advantageous to give the reliable result in a very short time. ${ }^{10}$

\section{Analytical and purification applications -}

Experimental designs are also useful in analytical and purification process with the help of chromatographic techniques. Recently Cole et al. has showed the use of this protocol in the optimization of high- throughput semi preparative LC method for the purification of compounds which results from library synthesis. ${ }^{11} \mathrm{~A}$ recent application of experimental design has been the optimization of fusion protein purification with the help of metal affinity chromatography. 12

\section{Biological applications -}

By optimizing pharmaceutical products or formulations, or process, screening design such as full factorial design, fractional factorial design, and Plackett-Burman designs are used. ${ }^{13-15}$ Response surface design such as central composite and Box-Benhken designs are also applied to optimize the biological process and pharmaceutical products. ${ }^{16-19}$

A further new application of this approach is beneficial in PAT - related research. Designs such as full factorial was used in homogenization process of pharmaceutical suspension of freeze drying process, powder blending process, and of a fluid bed granulation process. ${ }^{20,21}$

\section{Drug Delivery System:}

Experimental designs are also applicable in the development of various pharmaceutical formulations such as, nanoparticles, phytosomes, microspheres, liposomes, micelles, films, nanostructured lipid carriers and tablets as mentioned in table 1.

\section{NANOPARTICLES:}

Sharma Shaveta et al optimized and developed solid lipid nanoparticle (SLN)as carrier of pioglitazone for amplification of oral efficacy. In this study, the formulation was optimized by using three factors such as lipid, surfactant and homogenization speed. The results showed that optimized formulation had higher therapeutic effectiveness after encapsulating into SLN formulation. ${ }^{22}$ JifuHao et al., applied Central composite design to optimize a novel baicalin loaded SLNs prepared with the coacervation technique. The researcher selected lipid and drug: lipid ratio as independent variables for the optimization and concluded that, incorporation of baicalin into SLN carrier system could improve the bioavailability. ${ }^{23}$ Fengzhen Wang et al, used BoxBehnken design to optimized and developed methazolamide SLN (MTZ-SLNs) eye drops by defining the relationship between design factors and experimental results. The amount of glycerol monostearate (GMS), phospholipid, and surfactant were considered as the independent variables. The acute eye irritation study found MTZ-SLNs to be nonirritation and also concluded that, it is feasible to prepare MTZ into topical eye drops taking SLNs as a carrier. ${ }^{24}$ Tanmoy Das et al., used full factorial design to develop and optimized Solid Lipid Nanoparticles based alendronate in situ gel as an implantable drug delivery system for the treatment of osteoporosis. The percentage of polymers, PF127 \& PF-68, was used as independent variables (A and B) respectively as independent variables. From the results, they were concluded that alendronate - solid lipid nanoparticle based in- situ gel for the treatment of osteoporosis could be suitable drug delivery system over conventional dosage. ${ }^{25}$

\section{PHYTOSOMES:}

Pooja Jain et al., applied quality by design to optimize and developed the phytosomal gel of Aloe-Vera extract for improved topical delivery by fixing the amount of Aloe-Vera extract and ethanol and by varying the concentration of lecithin and rotational speed. On the basis of in-vitro release the researchers found that the phytosomal formulation had better therapeutic potential as compared to conventional. ${ }^{26}$ Sushila Rathee and Anjoo Kamboj used BoxBenhken design to optimized and developed anti-diabetic phytosomes. In this study, the prepared phytosomes formulations were optimized using three variables: Lipid (1: $3)$, temperature $\left(60^{\circ} \mathrm{C}\right)$ and time $(2.5 \mathrm{~h})$.From the results, the researchers concluded that the polyhedral phytosomes preparation can provide a convenient and safe alternative to the conventional dosage form. ${ }^{27}$ Darshan R. Telange et al., applied full factorial design to formulate and characterized apigenin-phospholipid phytosome (APLC) for improved solubility, in vivo bioavailability, and antioxidant potential. The formulations were developed by fixing the amount of drug: phospholipids ratio andtemperature on the extent of apigenin incorporation (\% yield). The optimized formulation showed improvement in solubility, oral bioavailability, and pharmacological properties. ${ }^{28}$ Mohammad H. Shariare et al., used DoE to Optimized and developed Epigallocatechin3Gallate (EGCG) nano -phytosome. They found that the addition rate, stirring temperature and phospholipid concentration were the most critical parameters affecting both average particle size and drug loading on phytosome. ${ }^{29}$

\section{MICROSPHERES:}

N. Mennini et al., applied Quality by design approach for developing chitosan-Calcium alginate microspheres for colon delivery of celecoxib-hydroxypropyl-b-cyclodextrin-PVP complex. Experimental design was used to investigate the combined effect of percentage of ca-alginate, $\mathrm{CaCl} 2$, chitosan and time of cross-linking. They demonstrated that the prepared formulation of colon-targeted CXB microspheres suitably adaptable to obtain the desired drug release profile. ${ }^{30}$ AashimaHooda et al., used experimental design to optimized and evaluate the gastroretentive ranitidine $\mathrm{HCl}$ microspheres. They studied the effect of drug polymer ratio, concentration of sodium tripolyphosphate and stirring speed on the formulation and concluded that, the statistical tools like design expert are helpful in understanding the interactions between different independent variables and for rapid formulation development. 31

Dana Hales et al, used a QbD approach for the optimization of enoxaparin sodium loaded polymeric microspheres for colon-specific delivery. The Process parameters studied were Eudragit ${ }^{\circledR}$ FS-30D/Eudragit ${ }^{\circledR}$ RS-PO ratio, poly (vinyl alcohol) concentration and sodium chloride concentration. This study demonstrated the usefulness of QbD approach in pharmaceutical drug development. ${ }^{32}$

\section{LIPOSOMES:}

Naghmeh Samadi et al., used Box- Behnken design to optimized and formulate vitamin K1 oxide-loaded nanoliposomes for transdermal delivery. The independent variables selected were the ratio of phospholipid to cholesterol, drug concentration a well sonication time. The researcher found that optimized nano liposomes formulation has higher drug release in a controlled manner as compared 
to solution. ${ }^{33}$ ArpitaBhattacharjee et al., applied Full factorial design to optimized and developed besifloxacin hydrochloride loaded liposomal gel prepared by thin film hydration method. The effect of independent factors i.e. soya lecithin to cholesterol ratio and lipid to drug ratio on characteristics of liposomes were examined. From this study concluded that, the prepared liposomal gel could be used as an effective ocular drug delivery system. ${ }^{34}$

M.L. Gonzalez-Rodriguez et al., applied fractional factorial design to study the formulation variables which influence the coating process of lidocaine liposomes. The variables which selected for optimization were the concentration of coating solution, the dripping rate of solution on the liposome colloidal dispersion, stirring rate, time and amount of drug entrapped into liposomes. ${ }^{35}$ Anil Kumar Sahu and Vishal Jain used Plackett- Burman design for the screening of process variables in the fabrication of gedunin- loaded liposomes. They selected three formulation factors for optimization such as drug concentration, lipid concentration, cholesterol/lecithin ratio and concluded that, Plackett Burman design was a beneficial to identify the independent factors which affect the response variables and also identify the significant factor. ${ }^{36}$

Table 1: Experimental design used in various formulations

\begin{tabular}{|c|c|c|c|c|}
\hline Formulations & API & $\begin{array}{l}\text { Experimental } \\
\text { Design }\end{array}$ & Factors & Reference \\
\hline \multirow{4}{*}{ NANOPARTICLES } & Pioglitazone & $\mathrm{BBD}$ & $\begin{array}{l}\text {-Lipid } \\
\text {-Surfactant } \\
\text {-Homogenization speed }\end{array}$ & {$[22]$} \\
\hline & Baicalin & CCD & $\begin{array}{l}\text {-Lipid } \\
\text {-Drug: Lipid ratio }\end{array}$ & {$[23]$} \\
\hline & Methazolamide & BBD & $\begin{array}{l}\text {-GMS } \\
\text {-Phospholipid } \\
\text {-Surfactant }\end{array}$ & {$[24]$} \\
\hline & Alendronate & FFD & $\begin{array}{l}-\% \text { of PF-127 (Polymer) } \\
-\% \text { Of PF-68 (Polymer) }\end{array}$ & [25] \\
\hline \multirow{4}{*}{ PHYTOSOMES } & Aloevera extract & CCD & $\begin{array}{l}\text {-Conc. of Lecithin } \\
\text {-Speed of rotation }\end{array}$ & {$[26]$} \\
\hline & Flavonoid extract & BBD & $\begin{array}{l}\text {-Lipid } \\
\text {-Temperature \& Time }\end{array}$ & [27] \\
\hline & Apigenin & FFD & $\begin{array}{l}\text {-Drug: Phospholipid ratio } \\
\text {-Temperature }\end{array}$ & {$[28]$} \\
\hline & EGCG & FFD & $\begin{array}{l}\text {-Conc. of Phospholipid } \\
\text {-Addition rate } \\
\text {-Stirring temperature }\end{array}$ & [29] \\
\hline \multirow{3}{*}{ MICROSPHERE } & $\begin{array}{l}\text { Celecoxib- } \\
\text { hydroxypropyl-b- } \\
\text { cyclodextrin-PVP } \\
\text { complex }\end{array}$ & $\mathrm{QbD}$ & $\begin{array}{l}\text {-\% of Calcium alginate } \\
\text {-Calcium of chloride } \\
\text {-Chitosan } \\
\text {-Time of cross-linking } \\
\end{array}$ & [30] \\
\hline & Ranidine HCL & CCD & $\begin{array}{l}\text {-Drug : polymer ratio } \\
\text {-Conc. of Sodium tripolyphosphate } \\
\text {-Stirring speed }\end{array}$ & {$[31]$} \\
\hline & $\begin{array}{l}\text { Enoxaparin } \\
\text { sodium }\end{array}$ & CCD & $\begin{array}{l}\text {-Eudragit@ FS-30D / Eudragit@ RS-PO ratio } \\
\text {-Conc. of Poly(vinylalcohol) } \\
\text {-Conc. of Sodium chloride }\end{array}$ & {$[32]$} \\
\hline \multirow{5}{*}{ LIPOSOMES } & Vit. $K_{1}$ Oxide & BBD & $\begin{array}{l}\text {-PC/CHO ratio } \\
\text {-Conc. of Drug } \\
\text {-Sonication time }\end{array}$ & [33] \\
\hline & Bacifloxacin HCL & FFD & $\begin{array}{l}\text {-Soya lecithin/cholesterol ratio } \\
\text {-Lipid/Drug ratio }\end{array}$ & {$[34]$} \\
\hline & Lidocaine & FrFD & $\begin{array}{l}\text {-Conc. of Coating Soln } \\
\text {-Dripping rate } \\
\text {-Stirring rate } \\
\text {-Time } \\
\text {-Conc. of drug }\end{array}$ & [35] \\
\hline & Gedunin & PBD & $\begin{array}{l}\text {-Conc. of Drug } \\
\text {-Conc. of Lipid } \\
\text {-Cholesterol/lecithin ratio }\end{array}$ & [36] \\
\hline & Valsartan & BBD & $\begin{array}{l}\text {-Ratio of surfactant } \\
\text {-Ratio of solid carrier }\end{array}$ & [37] \\
\hline
\end{tabular}




\begin{tabular}{|c|c|c|c|c|}
\hline \multirow{3}{*}{ MICELLS } & & & -Total mass of solid carrier & \\
\hline & $\begin{array}{l}\text { Lopinavir Vit.E } \\
\text { TPGS }\end{array}$ & CCD & $\begin{array}{l}\text {-TPGS: Drug ratio } \\
\text {-Rotational speed }\end{array}$ & [38] \\
\hline & Paclitaxel & BBD & $\begin{array}{l}\text {-Effect of pressure } \\
-\mathrm{ScCO}_{2} \text { release rate } \\
-\mathrm{Vol}^{\mathrm{m}} \text { ratio of water against } \mathrm{ScCO}_{2}\end{array}$ & [39] \\
\hline \multirow{4}{*}{ FILMS } & Tenoxicam & FFD & $\begin{array}{l}\text {-Conc. of Chitosan } \\
\text {-Conc. of PVP }\end{array}$ & {$[40]$} \\
\hline & Asiaticoside & BBD & $\begin{array}{l}\text {-PVA conc. } \\
\text {-PEG conc. } \\
\text {-Freeze thaw cycle days }\end{array}$ & [41] \\
\hline & Zolmitriptan & FFD & $\begin{array}{l}\text {-PEG } 400 \\
\text {-Sucralose }\end{array}$ & [42] \\
\hline & Tolterodine & BBD & $\begin{array}{l}\text {-Carbopol } 980 \\
\text {-Hydroxypropyl cellulose } \\
\text {-HPMC } \\
\text {-Tween } 80\end{array}$ & [43] \\
\hline \multirow{4}{*}{$\begin{array}{l}\text { NANO } \\
\text { STRUCTURED } \\
\text { LIPID CARRIERS }\end{array}$} & Methotrexate & BBD & $\begin{array}{l}\text {-Amount of lipid } \\
\text {-Surfactant } \\
\text {-Drug }\end{array}$ & [44] \\
\hline & Lurasidone HCL & BBD & $\begin{array}{l}\text {-Conc. of lipid } \\
\text {-Surfactant } \\
\text {-Sonication time }\end{array}$ & [45] \\
\hline & Sulforaphane & BBD & $\begin{array}{l}\text {-Lipid conc. } \\
\text {-Surfactant conc. } \\
\text {-Sonication time }\end{array}$ & [46] \\
\hline & Telmisartan & BBD & $\begin{array}{l}\text {-Lipid conc. } \\
\text {-Surfactant conc. } \\
\text {-Sonication time }\end{array}$ & [47] \\
\hline \multirow{3}{*}{ TABLETS } & $\begin{array}{l}\text { Indapamide } \\
\text { hemihydrate }\end{array}$ & CCD & $\begin{array}{l}\text {-Binder Conc. } \\
\text {-Matrix Conc. } \\
\text {-Grade of indapamide }\end{array}$ & [48] \\
\hline & Valsartan & CCD & $\begin{array}{l}\text {-Conc. of pH modifier } \\
\text {-Conc. of Solubility }\end{array}$ & [49] \\
\hline & Domperidone & FFD & $\begin{array}{l}\text {-Polymer Conc. } \\
\text {-Drug Conc. }\end{array}$ & [50] \\
\hline
\end{tabular}

(BBD- Box - Behnken design, CCD- Central composite design, FFD- Full factorial design, QbD- Quality by design, FrFD- Fractional factorial design)

\section{MICELLS:}

Yoon Tae Goo et al., applied Box- Behnken design to optimize solid self-Dispersing micelles (S-SDM) for enhancing the dissolution and oral bioavailability of valsartan. Experiment was performed by using three independent variables such as the ratio of surfactants, ratio of solid carriers, and total mass of solid carriers. In this study they concluded that, optimized S-SDM could be a selectable candidate for developing water insoluble drugs in reduced quantity. ${ }^{37} \mathrm{HitendraMahajan}$ and Payal Patil used central composite design to optimized Lopinavir Vitamin E TPGS micelle. In this study, they selected two parameters such as TPGS: drug ratio and rotational speed as independent variables. The study concluded that micelles have a wide scope for the development of such formulations can overcome challenges of current highly active anti- retroviral therapy (HAART). ${ }^{38 Z h e n ~ J i a o ~ e t ~ a l ., ~}$ applied Box-Behnken design to prepared and optimized Drug loaded micelles through supercritical carbon dioxide evaporation method. In this study, authors selected three factors such as the effects of pressure, $\mathrm{ScCO} 2$ (super critical carbon-dioxide) release rate and the volume ratio of water against ScCO2. The study revealed that, the optimized micelles formulation showed a narrow size distribution, regularly spherical shape, and also the sustained release of paclitaxel from the micelles. ${ }^{39}$

\section{FILMS:}

Lubna Y. Ashri et al., used factorial design to optimize and evaluate Buccal Mucoadhesive tenoxicam (TNX) local delivery system using two independent factors i.e. Chitosan and PVP concentrations. This study revealed that, the optimized TNX mucoadhesive buccal film could be suitable for oral therapy and could be a means to overcome the side effects of orally delivered drug. ${ }^{40} \mathrm{Afnan}$ Sh. Ahmed et al., prepared and optimize PVA-PEG physically cross-linked hydrogel film as a wound dressing. The independent variables used in this study were PVA concentration (\%), PEG concentration (\%), and freeze-thaw cycles (days, 1 cycle=1 day). From this study it was concluded that, the optimized batch of PVA/PEG hydrogel had a high capacity to absorb fluid and was elastic and safe therefore, it possesses an immense potential as a wound dressing material. ${ }^{41}$

Vipul D. Prajapati et al., applied factorial design to developed and optimize Pullulan based oral thin film formulation of 
zolmitriptan by selecting independent variables such as PEG 400 (X1) and sucralose (X2). From this study it was concluded that, pullulan can be successfully utilized at labscale for the formulation of oral thin film of zolmitriptan using PEG 400 and sucralose as best compatible plasticizer and sweetener, respectively. ${ }^{42 X i m i n g ~ L i u ~ e t ~ a l ., ~ u s e d ~ B o x ~-~}$ Behnken design to developed and optimize transparent film forming hydrogels and their consequence on stratum corneum. Carbopol 980, hydroxypropylcellulose, hydroxypropyl methyl cellulose (HPMC) and Tween 80 were used as independent variables. From this study, authors concluded that optimization of tolterodine hydrogels preparation is simple and effective with the help of ternary phase diagram and response surface methodology. 43

\section{NANOSTRUCTURED LIPID CARRIER:}

Mara Ferreira et al., applied Box- Behnken design to optimize nanostructured lipid carriers which are loaded with methotrexate. They selected three parameters such as amount of liquid lipid, amount of surfactant and amount of methotrexate as independent variables. Researchers revealed that, the optimized formulation of methotrexate was appropriate for systemic and topical administration. ${ }^{44}$ ImranaJazuli et al., used to optimize nanostructured lipid carriers of Lurasidone Hydrochloride for brain targeting and to study the in-vitro, in-vivo protocol. In this study, they had selected three parameters such as lipid concentration, surfactant, and sonication times for the optimization. The results showed that, the intranasal route can be suitable for the delivery of drug directly to the brain and also increased the efficacy of drug in brain. ${ }^{45}$

Kriti Soni et al., applied Box-Behnken design to optimize and developed nanostructured lipid carriers loaded with sulforaphane for improved oral efficacy against cancer. In this study, researcher selected three variables for the optimization: lipid concentration, surfactant concentration and sonication time. The results revealed that, nanostructured lipid carriers loaded with sulforaphane could be an important strategy for the management of cancer by oral delivery. 46

Chhitij Thapa et al., used Box-Behnken design to formulate and optimize nano structured lipid carriers of telmisartan to increase its oral bioavailability by selecting three independent variables i.e. total lipid concentration, surfactant concentration, and sonication time. From the results, it was concluded that, the bioavailability of nanostructured lipid carriers loaded with telmisartan was increased as compared to the marketed formulation. 47

\section{TABLETS:}

Packa Antovska et al., used Central Composite Face Design (CCD) to developed and optimize novel controlled-release matrix tablet formulation for indapamide hemihydrate. From the results, it was concluded that concentration of the chosen high-viscosity polymer, such as hydroxyl-ethylcellulose, play an important role in the dissolution profile of indapamide. 48

Mehtap Saydam \& Sevgi Takka applied central composite design to developed and evaluate $\mathrm{pH}$-independent controlled release matrix tablet of valsartan and its in-vitro study. Researchers were selected two variables: the concentration of $\mathrm{pH}$ modifier sodium citrate and the concentration of solubility enhancer. From the results, it was observed that, for 12 hours of controlled release, HPMC E4M was found to be most suitable hydrophilic matrix polymer. ${ }^{49}$

Hemlata G. Patil et al., used factorial design for the formulation and development of oro disperse and sustained release tablet loaded with domperidone. They selected two independent variables i.e. polymer concentration and drug concentration for the optimization. The optimized formulation showed disintegration time of 21 seconds and matrix controlled drug release for $9 \mathrm{~h} .50$

\section{OTHERS:}

Kamlesh Wadher et al., prepared nine emulgel formulations of Pongamia pinnata according to a $3^{2}$ factorial design employing the qualitative factors and levels. Two independent variables were evaluated as amount of Carbapol and amount of Emulsified agent; Viscosity and spreadability were selected as the dependent variables. From the observed results it was concluded that there is increase in the drug release in optimized formulation with respect to time. 51

Abhishek Sharma et al., used Box-Behnken design to Developed and optimized nanoemulsion based gel for enhanced transdermal delivery of nitrendipine. They were selected oil, surfactant and co-surfactant as independent variables for the optimization. This study revealed that, the prepared nanoemulsion gel could be used as a carrier for transdermal delivery of nitrendipine. ${ }^{52}$

Trivedi S et al., prepared Thymoquinone loaded polymerlipid hybrid vesicles to enhance the permeation and anticancer potency. The formulations were prepared by ethanol injection technique using $3^{2}$ factorial designs. The results concluded that the optimized nano carrier loaded formulation could be considered as a promising formulation for delivery of drug with enhanced treatment of cancer with reduced toxicity. 53

Yanping Deng et al., applied Central composite design to prepared and optimized Fat-soluble Vitamins lipid Injectable emulsion. In this study, the percentage of emulsifier (X1), homogenization pressure (X2) and homogenization recirculation (X3) were selected as independent variables. From this study, they were concluded that by using Quality by design approach, lipid injectable emulsion for fat soluble vitamins was successfully prepared. ${ }^{54}$

\section{CONCLUSION:}

Experimental design is a method used to optimize the formulation to getting effective pharmaceutical product. Experimental design can accurately analyze the all factors which are to be considered while performing the experimentation. This method is economical and less tedious than traditional methods used for optimization. In future, experimental design plays an important role for developing various pharmaceutical formulations. In this review article, we describe the type of experimental design and emphasize on the applications of experimental design in drug delivery system and factors to be considered while performing particular formulation such as phytosomes, liposomes, microspheres etc.

Acknowledgement: The authors are express their gratitude to Smt. Kishoritai Bhoyar College of Pharmacy, Kamptee, Nagpur.

\section{Conflict of Interest: There are no conflicts of interest}

\section{REFERENCES:}

1. Singh B, Kumar R, Ahuja N, Optimizing drug delivery systems using systematic "design of experiments." Part I: fundamental aspects. Crit Rev Ther Drug Carrier Syst. 2005; 22(1):27105.doi:10.1615/critrevtherdrugcarriersyst.v22.i1.20. PMID: 15715503.

2. Lewis GA, Mathieu D, Phan-Tan-Luu, R., Pharmaceutical Experimental Design. Marcel Dekker Inc., New York, 1999; 
14(2):93-94, doi.org/10.1002/(SICI)1099-

128X(200003/04)14:2<93::AID-CEM574>3.0.C0;2-F

3. Bezerra MA, Santelli RE, Oliveira EP, Villar LS, Escaleira LA. Response surface methodology (RSM) as a tool for optimization in analytical chemistry.Talanta. 2008 Sep 15; 76(5):965-77. doi: 10.1016/j.talanta.2008.05.019. Epub 2008 May 21. PMID: 18761143.

4. Candioti LV, De Zan MM, Cámara MS, Goicoechea HC. Experimental design and multiple response optimization. Using the desirability function in analytical methods development.Talanta.2014 Jun; 124:123-38.doi: 10.1016/j.talanta.2014.01.034. Epub 2014 Feb 12. PMID: 24767454.

5. Politis SN, Colombo P, Colombo G, Rekkas DM. Design of experiments (DoE) in pharmaceutical development. Drug Develop Ind Pharm. 2017 Jun; 43(6):889-901. doi: 10.1080/03639045.2017.1291672. Epub 2017 Feb 23. PMID: 28166428.

6. Heyden YV, Perrin C, Massart DL, Optimization strategies for HPLC and CZE, in: K. Valkó (Ed.), Handbook of Analytical Separations, vol. 1, Separation Methods in Drug Synthesis and Purification, Elsevier, Amsterdam, 2000, pp. 163-212.

7. Dejaegher B, Heyden YV, The use of experimental design in separation science, ActaChromatogr. 2009; 21:161-201.

8. Dejaegher B, Durand A, Vander Heyden Y. Experimental design in method optimization and robustness testing. Chemometric methods in capillary electrophoresis. 2009 Oct 22:11-74.

9. Pinheiro Ade S, de Andrade JB. Development, validation and application of a SDME/GC-FID methodology for the multiresidue determination of organophosphate and pyrethroid pesticides in water.Talanta. 2009 Oct 15; 79(5):1354-9. doi: 10.1016/j.talanta.2009.06.002. Epub 2009 Jun 9. PMID: 19635370

10. Fukuda IM, Pinto CF, Moreira CD, Saviano AM, Lourenço FR. Design of experiments (DoE) applied to pharmaceutical and analytical quality by design (QbD). Brazilian Journal of Pharmaceutical Sciences. 2018 Nov 8; 54. https://doi.org/10.1590/s2175-97902018000001006

11. Cole DC, Pagano N, Kelly MF, Ellingboe J. Use of design of experiments to optimize high-throughput semipreparative LC and LC/MS methods. Journal of combinatorial chemistry. 2004 Jan 12; 6(1):78-82. https://doi.org/10.1021/cc034013v

12. Shukla AA, Sorge L, Boldman J, Waugh S. Process characterization for metal-affinity chromatography of an Fc fusion protein: A design-of-experiments approach. Biotechnology and applied biochemistry. 2001 0ct; 34(2):71-80. https://doi.org/10.1042/BA20010019

13. Derakhshandeh K, Erfan M, Dadashzadeh S. Encapsulation of 9nitrocamptothecin, a novel anticancer drug, in biodegradable nanoparticles: factorial design, characterization and release kinetics. European journal of pharmaceutics and biopharmaceutics. 2007 Apr 1; 66(1):34-41 https://doi.org/10.1016/j.ejpb.2006.09.004

14. Stensrud G, Sande SA, Kristensen S, Smistad G. Formulation and characterisation of primaquine loaded liposomes prepared by a $\mathrm{pH}$ gradient using experimental design. International journal of pharmaceutics. 2000 Apr 5; 198(2):213-28. https://doi.org/10.1016/S0378-5173(00)00338-0

15. Tajber L, Corrigan OI, Healy AM. Spray drying of budesonide, formoterolfumarate and their composites-II. Statistical factorial design and in vitro deposition properties.International journal of pharmaceutics. 2009 Feb 9; 367(1-2):86-96. https://doi.org/10.1016/j.ijpharm.2008.09.029

16. Reddy LV, Wee YJ, Yun JS, Ryu HW. Optimization of alkaline protease production by batch culture of Bacillus sp. RKY3 through Plackett-Burman and response surface methodological approaches.Bioresource technology. 2008 May 1; 99(7):2242-9. https://doi.org/10.1016/j.biortech.2007.05.006

17. Ahuja M, Yadav M, Kumar S. Application of response surface methodology to formulation of ionotropically gelled gum cordia/gellan beads. Carbohydrate Polymers. 2010 Mar 25; 80(1):161-7. https://doi.org/10.1016/j.carbpol.2009.11.005

18. Stensrud G, Sande SA, Kristensen S, Smistad G. Formulation and characterisation of primaquine loaded liposomes prepared by a $\mathrm{pH}$ gradient using experimental design. International journal of pharmaceutics. 2000 Apr 5; 198(2):213-28. https://doi.org/10.1016/S0378-5173(00)00338-0
19. Imandi SB, Bandaru VR, Somalanka SR, Garapati HR. Optimization of medium constituents for the production of citric acid from byproduct glycerol using Doehlert experimental design. Enzyme and Microbial Technology. 2007 Apr 3; 40(5):1367-72. https://doi.org/10.1016/j.enzmictec.2006.10.012

20. De Beer TR, Bodson C, Dejaegher B, Walczak B, Vercruysse P, Burggraeve A, Lemos A, Delattre L, Vander Heyden Y, Remon JP, Vervaet C. Raman spectroscopy as a process analytical technology (PAT) tool for the in-line monitoring and understanding of a powder blending process. Journal of pharmaceutical and biomedical analysis. 2008 Nov 4; 48(3):7729. https://doi.org/10.1016/j.jpba.2008.07.023

21. Burggraeve A, Van Den Kerkhof T, Hellings M, Remon JP, Vervaet C, De Beer T. Evaluation of in-line spatial filter velocimetry as PAT monitoring tool for particle growth during fluid bed granulation. European Journal of Pharmaceutics and Biopharmaceutics. 2010 Sep 1; 76(1):138-46.. https://doi.org/10.1016/j.ejpb.2010.06.001

22. Shaveta S, Singh J, Afzal M, Kaur R, Imam SS, Alruwaili NK, Alharbi KS, Alotaibi NH, Alshammari MS, Kazmi I, Yasir M. Development of solid lipid nanoparticle as carrier of pioglitazone for amplification of oral efficacy: formulation design optimization, in-vitro characterization and in-vivo biological evaluation. Journal of Drug Delivery Science and Technology. 2020 Jun 1; 57:101674 https://doi.org/10.1016/j.jddst.2020.101674

23. Hao J, Wang F, Wang X, Zhang D, Bi Y, Gao Y, Zhao X, Zhang Q. Development and optimization of baicalin-loaded solid lipid nanoparticles prepared by coacervation method using central composite design. European Journal of Pharmaceutical Sciences. 2012 Sep 29; 47(2):497-505 https://doi.org/10.1016/j.ejps.2012.07.006

24. Wang F, Chen L, Jiang S, He J, Zhang X, Peng J, Xu Q, Li R. Optimization of methazolamide-loaded solid lipid nanoparticles for ophthalmic delivery using Box-Behnken design. J Liposome Res. 2014 Sep; 24(3):171-81. doi: 10.3109/08982104.2014.891231. Epub 2014 Mar 10. PMID: 24611687.)

25. Das T, Venkatesh MP, Kumar TP, Koland M. SLN based alendronate in situ gel as an implantable drug delivery system-A full factorial design approach. Journal of Drug Delivery Science and Technology. 2020 Feb 1; 55:101415. https://doi.org/10.1016/j.jddst.2019.101415.

26. Jain P, Taleuzzaman M, Kala C, Kumar Gupta D, Ali A, Aslam M. Quality by design (Qbd) assisted development of phytosomal gel of aloe vera extract for topical delivery. Journal of Liposome Research.2020 Nov 12:1-8.doi: 10.1080/08982104.2020.1849279. Epub ahead of print. PMID: 33183121.

27. Rathee S, Kamboj A. Optimization and development of antidiabeticphytosomes by the Box-Behnken design. Journal of liposome research. 2018 Apr 3; 28(2):161-72.doi: 10.1080/08982104.2017.1311913. Epub 2017 Apr 17. PMID: 28337938.

28. Telange DR, Patil AT, PetheAM, Fegade H, Anand S, Dave VS. Formulation and characterization of an apigenin-phospholipid phytosome (APLC) for improved solubility, in vivo bioavailability, and antioxidant potential.Eur J Pharm Sci. 2017 Oct 15; 108:36-49. doi: 10.1016/j.ejps.2016.12.009. Epub 2016 Dec 8. PMID: 27939619.)

29. H Shariare M, Afnan K, Iqbal F, A Altamimi M, Ahamad SR, S Aldughaim M, K Alanazi F, Kazi M. Development and Optimization of Epigallocatechin-3-Gallate (EGCG) Nano Phytosome Using Design of Experiment (DoE) and Their In Vivo Anti-Inflammatory Studies. Molecules. 2020 Nov 20; 25(22):5453. doi: 10.3390/molecules25225453. PMID: 33233756; PMCID: PMC7699940.

30. Mennini N, Furlanetto S, Cirri M, Mura P. Quality by design approach for developing chitosan-Ca-alginate microspheres for colon delivery of celecoxib-hydroxypropyl- $\beta$-cyclodextrin-PVP complex. Eur J Pharm Biopharm. 2012 Jan; 80(1):67-75. doi: 10.1016/j.ejpb.2011.08.002. Epub 2011 Aug 16. PMID: 21864681.

31. Hooda A, Nanda A, Jain M, Kumar V, Rathee P. Optimization and evaluation of gastroretentive ranitidine $\mathrm{HCl}$ microspheres by using design expert software. Int J BiolMacromol. 2012 Dec; 
51(5):691-700. doi: 10.1016/j.ijbiomac.2012.07.030. Epub 2012 Aug 3. PMID: 22903013.)

32. Hales D, Vlase L, Porav SA, Bodoki A, Barbu-Tudoran L, Achim M, Tomuț̆ I. A quality by design (QbD) study on enoxaparin sodium loaded polymeric microspheres for colon-specific delivery. Eur J Pharm Sci. 2017 Mar 30; 100:249-261. doi:

10.1016/j.ejps.2017.01.006. Epub 2017 Jan 11. PMID: 28088371.)

33. Samadi N, AberoomandAzar P, Waqif Husain S, Maibach HI, Nafisi $\mathrm{S}$. Experimental design in formulation optimization of vitamin $\mathrm{K}_{1}$ oxide-loaded nanoliposomes for skin delivery.Int J Pharm. 2020 Apr 15; 579:119136. doi: 10.1016/j.ijpharm.2020.119136. Epub 2020 Feb 11. PMID: 32057891.

34. Bhattacharjee A, Das PJ, Dey S, Nayak AK, Roy PK, Chakrabarti S, Marbaniang D, Das SK, Ray S, Chattopadhyay P, Mazumder B. Development and optimization of besifloxacin hydrochloride loaded liposomal gel prepared by thin film hydration method using 32 full factorial design. Colloids and Surfaces A: Physicochemical and Engineering Aspects. 2020 Jan 20 585:124071,doi.org/10.1016/j.colsurfa.2019.124071.

35. González-Rodríguez ML, Barros LB, Palma J, González-Rodríguez PL, RabascoAM.Application of statistical experimental design to study the formulation variables influencing the coating process of lidocaineliposomes.Int J Pharm. 2007 Jun 7; 337(1-2):336-45. doi: 10.1016/j.ijpharm.2007.01.024. Epub 2007 Jan 20. PMID: 17317050.)

36. Sahu AK, Jain V. Screening of process variables using PlackettBurman design in the fabrication of gedunin-loaded liposomes.Artif Cells NanomedBiotechnol. 2017 Aug; 45(5):1011-1022. doi: 10.1080/21691401.2016.1200057. Epub 2016 Dec 4. PMID: 27917681.)

37. Goo YT, Park SY, Chae BR, Yoon HY, Kim CH, Choi JY, Song SH Choi YW. Optimization of solid self-dispersing micelle for enhancing dissolution and oral bioavailability of valsartan using Box-Behnken design. Int J Pharm. 2020 Jul 30; 585:119483. doi: 10.1016/j.ijpharm.2020.119483. Epub 2020 May 30. PMID: 32485217.)

38. Mahajan HS, Patil PH. Central composite design-based optimization of lopinavir vitamin E-TPGS micelle: In vitro characterization and in vivo pharmacokinetic study. Colloids Surf B Biointerfaces. 2020 Oct; 194:111149. doi: 10.1016/j.colsurfb.2020.111149. Epub 2020 May 26. PMID: 32590243.

39. Jiao Z, Zha X, Wang Z, Wang X, Fan W. Response Surface Modeling of Drug-Loaded Micelles Prepared Through Supercritical Carbon Dioxide Evaporation Method Using Box-Behnken Experimental Design. J NanosciNanotechnol.2019 Jun 1; 19(6):3616-3620. doi: 10.1166/jnn.2019.16124. PMID: 30744794.

40. Ashri LY, Amal El Sayeh F, Ibrahim MA, Alshora DH. Optimization and evaluation of chitosan buccal films containing tenoxicam for treating chronic periodontitis: In vitro and in vivo studies. Journal of Drug Delivery Science and Technology. 2020 Jun 1; 57:101720.doi.org/10.1016/j.jddst.2020.101720

41. Ahmed AS, Mandal UK, Taher M, Susanti D, Jaffri JM. PVA-PEG physically cross-linked hydrogel film as a wound dressing: experimental design and optimization. Pharm Dev Technol. 2018 Oct; 23(8):751-760. doi: 10.1080/10837450.2017.1295067. Epub 2017 Apr 5. PMID: 28378604

42. Prajapati VD, Chaudhari AM, Gandhi AK, Maheriya P. Pullulan based oral thin film formulation of zolmitriptan: Development and optimization using factorial design. Int J BiolMacromol. 2018 Feb; 107(Pt B):2075-2085. doi: 10.1016/j.ijbiomac.2017.10.082. Epub 2017 Oct 23. PMID: 29074082
43. Liu X, Fu L, Dai W, Liu W, Zhao J, Wu Y, Teng L, Sun F, Li Y. Design of transparent film-forming hydrogels of tolterodine and their effects on stratum corneum. Int J Pharm. 2014 Aug 25; 471(12):322-31. doi: 10.1016/j.ijpharm.2014.05.051. Epub 2014 Jun 2. PMID: 24882035

44. Ferreira M, Chaves LL, Lima SA, Reis S. Optimization of nanostructured lipid carriers loaded with methotrexate: A tool for inflammatory and cancer therapy. Int J Pharm. 2015 Aug 15; 492(1-2):65-72. doi: 10.1016/j.ijpharm.2015.07.013. Epub 2015 Jul 10. PMID: 26169145.

45. Jazuli I, Annu, Nabi B, Moolakkadath T, Alam T, Baboota S, Ali J. Optimization of Nanostructured Lipid Carriers of Lurasidone Hydrochloride Using Box-Behnken Design for Brain Targeting: In Vitro and In Vivo Studies. J Pharm Sci. 2019 Sep; 108(9):30823090. doi: 10.1016/j.xphs.2019.05.001. Epub 2019 May 8. PMID: 31077685

46. Soni K, Rizwanullah M, Kohli K. Development and optimization of sulforaphane-loaded nanostructured lipid carriers by the BoxBehnken design for improved oral efficacy against cancer: in vitro, ex vivo and in vivo assessments. Artif Cells NanomedBiotechnol. 2018; 46(sup1):15-31. doi: 10.1080/21691401.2017.1408124. Epub 2017 Nov 28. PMID: 29183147

47. Thapa C, Ahad A, Aqil M, Imam SS, Sultana Y. Formulation and optimization of nanostructured lipid carriers to enhance oral bioavailability of telmisartan using Box-Behnken design. Journal of Drug Delivery Science and Technology. 2018 Apr 1; 44:431-9. doi.org/10.1016/j.jddst.2018.02.003

48. Antovska P, Ugarkovic S, Petruševski G, Stefanova B, Manchevska B, Petkovska R, Makreski P. Development and experimental design of a novel controlled-release matrix tablet formulation for indapamide hemihydrate. Pharm Dev Technol. 2017 Nov;22(7):851-859. doi: 10.3109/10837450.2015.1089898. Epub 2015 Sep 24. PMID: 26402027

49. Saydam M, Takka S. Development and in vitro evaluation of $\mathrm{pH}$ independent release matrix tablet of weakly acidic drug valsartan using quality by design tools. Drug DevInd Pharm. 2018 Dec; 44(12):1905-1917. doi: 10.1080/03639045.2018.1496450. Epub 2018 Sep 10. PMID: 29969042.

50. Patil HG, Tiwari RV, Repka MA, Singh KK. Formulation and development of orodispersible sustained release tablet of domperidone. Drug DevInd Pharm. 2016; 42(6):906-15. doi: 10.3109/03639045.2015.1088864. Epub 2015

51. Wadher K, Dabre S, Supare V, Ghaywat S, Umekar M. Design and Development of Emulgel Containing Pongamiapinnata Extract Int. J. Pharm. Sci. Rev. Res., 66(2), January - February 2021; Article No. 12,: 68-73. doi:10.47583/ijpsrr.2021.v66i02.012

52. Sharma A, Singh AP, Harikumar SL. Development and optimization of nanoemulsion based gel for enhanced transdermal delivery of nitrendipine using box-behnken statistical design. Drug DevInd Pharm. 2020 Feb; 46(2):329-342. doi: 10.1080/03639045.2020.1721527. Epub 2020 Feb 5. PMID: 31976777

53. Trivedi S, Wadher K, Umekar M. Development of topical thymoquinone loaded polymer-lipid hybrid vesicular gel: invitro and ex-vivo evaluation. J Liposome Res. 2021 Jun 8:113.doi: 10.1080/08982104.2021.1929311

54. Deng Y, Zhong G, Wang Y, Wang N, Yu Q, Yu X. Quality by design approach for the preparation of fat-soluble vitamins lipid injectable emulsion. Int J Pharm. 2019 Nov 25; 571:118717. doi: 10.1016/j.ijpharm.2019.118717. Epub 2019 Oct 11. PMID: 31610279 